\title{
Fizik Öğretmen Adaylarının Isı, Sıcaklık ve İç Enerji ile ilgili Kavram Yanılgıları"
}

\section{Preservice Physics Teachers' Misconceptions about Heat, Temperature and Internal Energy}

\author{
Deniz GÜRÇAY ${ }^{* *}$, Etna GÜLBAŞ***
}

\begin{abstract}
ÖZ: Bu çalışmada, fizik öğretmen adaylarının 1sı, sıcaklık ve iç enerji kavramları ile ilgili anlama düzeyleri ve kavram yanılgıları incelenmiştir. Araştırmaya Fizik Eğitimi Anabilim Dalı'nın 1, 2, 3, 4 ve 5. sınıflarında öğrenim gören toplam 89 fizik öğretmen adayı katılmıştır. Çalışmada, fizik öğretmen adaylarının 1sı, sıcaklık ve iç enerji kavramları ile ilgili anlama düzeylerini ve kavram yanılgılarını belirlemek için Gülbaş (2013) tarafindan geliştirilmiş olan üç-aşamalı "Isı, Sıcaklık ve İç Enerji Kavram Testi" (ISİEKT) kullanılmıştır. Araştırmada, fizik öğretmen adaylarının ISİEKT'deki üç-aşamalı sorulara verdikleri doğru cevapların ortalama yüzdesi sıcaklık ile ilgili sorular için $\% 32$, iç enerji ile ilgili sorular için \%20, 1s ile ilgili sorular için \%5 olarak belirlenmiştir. Öğretmen adaylarının ISİEKT'deki üç-aşamalı sorulara verdikleri kavram yanılgısı cevaplarının ortalama yüzdesi sıcaklık ile ilgili sorular için \%12, iç enerji ile ilgili sorular için \%12, 1sı ile ilgili sorular için \%47 olarak tespit edilmiştir. Araştırma sonuçları, fizik öğretmen adaylarının 1Sı kavramını anlama düzeyinin çok düşük olduğunu göstermiştir. Ayrıca, öğretmen adaylarının "iç enerjinin cismin sahip olduğu 1sı miktarı" olduğuna ilişkin kavram yanılgılarının olduğu tespit edilmiştir.
\end{abstract}

Anahtar sözcükler: Isı, sıcaklık, iç enerji, anlama düzeyi, kavram yanılgısı.

ABSTRACT: In this study preservice physics teachers' understanding and misconceptions about heat, temperature and internal energy were investigated. A total of 89 preservice physics teachers who were first, second, third, fourth and fifth year students at Physics Education program, were participated in this study. The three-tier "Heat, Temperature and Internal Energy Concept Test" (HTIECT) which was developed by Gülbaş (2013) was used to determine preservice physics teachers' understandings and misconceptions about the concepts of heat, temperature and internal energy. In the study, the average percentage of the preservice physics teachers who gave correct answers to the three-tier questions in HTIECT was $32 \%$ for temperature questions, $20 \%$ for internal energy questions and 5\% for heat questions. The average percentage of preservice physics teachers who gave misconception answers to the three-tier questions in HTIECT was $12 \%$ for temperature questions, $12 \%$ for internal energy questions and $47 \%$ for heat questions. The results of the study revealed that that preservice physics teachers' understandings about the concept of heat was very low. Moreover, it was determined that preservice teachers had the misconception that "internal energy is the amount of heat an object has".

Keywords: Heat, temperature, internal energy, understanding, misconception.

\section{GíRiş}

Yapısalcı yaklaşımda vurgulandığı gibi, yeni öğrenilen bilgiler, öğrenenin zihninde daha önceden var olan kavramsal yapılar üzerine yapılandırılmaktadır. Ancak bu yapılandırma sürecinde, doğru öğrenmenin yanı sıra, eksik ya da hatalı öğrenmeler gerçekleşebileceği gibi giderilmesi oldukça zor olan kavram yanılgıları da oluşabilmektedir (Yağbasan ve Gülçiçek,

*Bu çalışma, 12-14 Eylül 2013 tarihinde gerçekleştirilen I. Ulusal Fizik Eğitimi Kongresi'nde sunulan bildirinin geliştirilmiş halidir.

*** Doç.Dr., Hacettepe Üniversitesi, Eğitim Fakültesi, OFMAE Bölümü e-posta: denizg@ hacettepe.edu.tr

*** Doktora öğrencisi, Hacettepe Üniversitesi, OFMAE Bölümü, e-posta: etnagulbas2@ yahoo.com.tr 
2003). Kavram yanılgılarının varlığı fen öğrenmeyi oldukça karmaşık bir süreç haline getirmektedir (Hollon ve Anderson, 1986). Öğrencilerin öğrenme süreci üzerinde önemli etkiye sahip olduğu bilinen öğretmenlerin, öğrencilerin sahip oldukları bu kavram yanılgılarını dikkate alması gerektiği vurgulanmaktadır (Libarkin ve Kurdziel, 2001). Dolayısıyla, fizik öğretmen adaylarının hizmet öncesinden itibaren ögrencilerin kavram yanılgıları hakkında bilgi sahibi olması ve bu kavram yanılgılarını nasıl giderilebileceğini bilmesi önemlidir. Ancak yapılan araştırmalarda sadece öğrencilerin değil öğretmen adaylarının da çeşitli kavram yanılgılarına sahip oldukları belirlenmiştir (Alwan, 2011; Gönen ve Akgün, 2005; Kaptan ve Korkmaz, 2001; Kartal, Öztürk ve Yalvaç, 2011; Keleş, Ertaş, Uzun ve Cansız, 2010). Fizik kavramları hakkında eksik veya yanlış bilgileri olan veya çeşitli kavram yanılgılarına sahip öğretmen adaylarının ileride öğrencilerine fizik kavramları ile ilgili doğru bilimsel bilgiler öğretebilmesi mümkün değildir (Kaptan ve Korkmaz, 2001). Bu nedenle, öğretmen adaylarının kavram yanılgılarının neler olduğunun incelenmesi gerektiğine inanılmaktadır.

\subsection{Isı, Sıcaklık ve İç Enerji ile ilgili Kavram Yanılgıları}

Öğrenmenin önündeki en büyük engellerden biri olan ve giderilmesi çok kolay olmayan kavram yanılgıları özellikle soyut yapısından dolayı fizikte çok sık karşılaşılan bir durumdur (Aydoğan, Güneş ve Gülçiçek, 2003; Gönen ve Akgün, 2005). Isı ve sıcaklık kavramları günlük konuşma dilinde çok kullanılan ve fizikte en çok karşılaşılan kavram yanılgıları arasındadır (Turgut ve Gürbüz, 2011; Yeşilyurt, 2006).

Isı, 1şık, kuvvet ve elektrik akımı ile ilgili kavram yanılgıları öğrencilerin sahip oldukları dirençli kavram yanılgıları arasındadır. Bazı öğrenciler 1sı, 1şık, kuvvet ve elektrik kavramı gibi soyut fizik kavramlarını açıklarken nesnelerin maddesel özellikleri ile ilgili bilgileri kullanmaktadır. Nesnelerin maddesel özellikleri veya maddesel davranışları kullanılarak açıklanan soyut fizik kavramları nesne-tabanlı kavramlar olarak adlandırılmaktadır (Reiner, Slotta, Chi, ve Resnick, 2000). Erickson (1979; 1980), çocukların 1sı ve sıcaklık kavramlarını açıklarken nesnelerin maddesel özellikleri ile ilgili bilgilerini kullandıklarını tespit etmiştir. Isı ve sıcaklık konusu ile ilgili kavram yanılgıları üzerine yapılmış bir çok çalışma (Clough ve Driver, 1985; Erickson, 1979; Erickson, 1980; Thomaz, Malaquias, Valente, ve Antunes, 1995), öğrencilerin sahip oldukları kavram yanılgılarının çoğunun nesne-tabanlı olduğunu ortaya koymuştur. $\mathrm{Bu}$ çalışmalarda, öğrencilerin, ısının nesnelerin içinde bulunan, nesnelerden taşınabilen ve bir nesneden diğerine geçebilen bir çeşit madde olduğuna inandı̆̆ı; nesnenin farklı hissedilmesini farklı sıcaklıklar olarak anladığı; sıcaklığı bir nesnenin yapıldığı malzemenin bir özelliği ve 1sının bir ölçüsü olarak düşündüğü belirlenmiştir. Ayrıca çeşitli çalışmalarda, öğrencilerin 1S1 ve sıcaklık kavramını ayırt etmekte zorlandıkları ve bu kavramları birbirinin yerine kullandıkları belirlenmiştir (Alwan, 2011; Appleton, 1984; Erickson, 1979; Erickson, 1980; Eryılmaz, 2010, Kaptan ve Korkmaz, 2001; Kartal et al. 2011; Kırıkkaya ve Güllü, 2008; Yeşilyurt, 2006). Isı ve sıcaklık kavramlarının ve bu kavramlar arasındaki farkın tam olarak bilinmemesinin sonucu olarak öğrencilerde farklı kavram yanılgılarının da olduğu görülmektedir. Örneğin bazı öğrenciler, bir nesneyi ısıtmanın daima sıcaklığını artıracağını, sıcaklığın transfer edilebileceğini düşünmektedir (Alwan, 2011; Thomaz et al. 1995).

Is1 ve sıcaklık konusu ilköğretim ve ortaöğretim kurumlarındaki öğrenciler kadar üniversite öğrencilerinin de öğrenmede güçlük çektikleri konulardan biridir (Gürses, Doğar, ve Yalçın, 2002; Kırıkkaya ve Güllü, 2008). Yapılan bazı çalışmalar, öğretmen adaylarının da 1sı ve sıcaklık konusu hakkında yukarıda bahsedilen kavram yanılgılarına sahip olduğunu ortaya koymuştur (Alwan, 2011; Gönen ve Akgün, 2005; Kaptan ve Korkmaz, 2001; Kartal et al. 2011; Keleş et al. 2010). Alan yazınında, 1sı ve sıcaklık konusuyla ilgili çalışmalar bulunmasına rağmen özellikle iç enerji konusu hakkındaki kavram yanılgılarını belirlemeye yönelik yeterli sayıda araştırma bulunmamaktadır. Ancak bazı çalışmalarda, 1sı ve iç enerji kavramının 
öğrenciler tarafından karıştırıldığı (Harrison, Grayson, ve Treagust, 1999) ve öğrencilerin iç enerjiyi bir cismin sahip olduğu 1sı miktarı olarak düşündüğü belirtilmiştir (Warren, 1972).

\subsection{Kavram Yanılgılarının Tespit Edilmesi}

Öğrencilerin kavram yanılgılarının tespit edilmesinde çeşitli ölçme yöntemlerinden faydalanılabilir. Alan yazınında kullanılan en yaygın ölçme araçları olarak; röportajlar (Osborne ve Gilbert, 1980), çoktan seçmeli testler (Başer, 1996; Beichner, 1994; Wiser, 1986), iki-aşamalı testler (Tan, Goh, Chia, ve Treagust, 2002; Tan, Taber, Goh, ve Chia, 2005) ve üç-aşamalı testler (Arslan, Cigdemoglu, ve Moseley, 2012; Eryılmaz, 2010; Eryılmaz ve Sürmeli, 2002; Peşman ve Eryılmaz, 2010) göze çarpmaktadır. Kavram yanılgılarının tespiti için kullanılan bütün tekniklerin her birinin hem dezavantajları hem de avantajları bulunmaktadır. $\mathrm{Bu}$ veri toplama araçlarından üç-aşamalı testlerin kavram yanılgılarının tespit edilmesinde daha etkili olduğu ifade edilmektedir (Arslan et al. 2012; Eryılmaz, 2010; Eryılmaz ve Sürmeli, 2002; Peşman ve Eryılmaz, 2010).

Üç-aşamalı testleri diğer ölçme araçlarından ayıran unsur, testteki üçüncü aşama sorularıdır. Üçüncü aşama soruları ile öğrencilerin önceki ilk iki aşamaya verdikleri cevaplardan emin olup olmadığı belirlenebilmektedir. Böylece, öğrencilerin testteki sorulara verdikleri doğru cevaplar ve kavram yanılgısı cevapları hakkında daha kesin yargılara ulaşmak mümkün olmaktadır (Hasan, Bagayoko ve Kelly, 1999). Öğrencilerin sorulara verdikleri cevapların kesinliği belirlenebildiği için bu yolla, kavram yanılgılarını hatalardan ve bilgi eksiklerinden dolayı yapılan hatalardan ayırt etmek daha kolay olmaktadır. Bu nedenle, üç-aşamalı testlerin, iki-aşamalı ve klasik çoktan seçmeli testlere kıyasla kavram yanılgılarını daha geçerli ölçtüğü ifade edilmektedir (Eryılmaz ve Sürmeli, 2002). Diğer taraftan, alan yazınında kullanımı çok yaygın olmayan üç-aşamalı testlerin geçerliği ve güvenirliği ile ilgili çeşitli problemlerin olduğu belirtilmektedir. Mümkün olduğunca az sayıda kavram yanılgısına odaklanan ve her kavram yanılgısını birden fazla soru ile ölçen testler geliştirilmesinin, üç-aşamalı testlerin bu problemlerini gidermede etkili bir yol olabileceği ifade edilmektedir (Eryılmaz, 2010). Kavram yanılgılarını hatalardan ve bilgi eksiklerinden dolayı yapılan hatalardan ayırt edebilmek için, bu araştırmada da az sayıda kavram yanılgısına odaklanan ve her kavram yanılgısını birden fazla soru ile ölçen üç-aşamalı test kullanılmasının gerekli olduğu düşünülmüştür.

Son yıllarda yapılan çalışmalarda da belirtildiği gibi, kavram yanılgıları, öğrencilerin fiziği öğrenmeleri üzerinde engeller oluşturmaktadır. Burada öğrencilerin kavram yanılgılarını gidermek ve fizik kavramları ile ilgili doğru öğrenmeler geliştirmelerine yardımcı olmak adına öğretmenlere önemli görevler düşmektedir. Bu açıdan fizikle ilgili kavram yanılgılarının neler olduğu ve bunların nasıl giderilebileceği ile ilgili yeterli bilgi ve donanıma sahip öğretmenlerin yetiştirilmesi oldukça önemlidir. Ancak yapılan bazı araştırmalar öğretmen adaylarının da kavram yanılgılarının olduğunu göstermektedir. Öğretmen adaylarının 1sı ve sıcaklık konusu hakkında sahip oldukları kavram yanılgılarını inceleyen çok sayıda araştırma olduğu halde, iç enerji kavramı ile ilgili yapılmış sınırlı sayıda araştırma bulunmaktadır. Bu çalışmada, fizik öğretmen adaylarının termodinamiğin temel kavramları olan 1s1, sıcaklık ve iç enerji kavramları ile ilgili anlama düzeylerinin ve kavram yanılgılarının belirlenmesi amaçlanmıştır.

\section{YÖNTEM}

\subsection{Araştırma Deseni}

$\mathrm{Bu}$ çalışma, fizik öğretmen adaylarının 1sı, sıcaklık ve iç enerji kavramlarını anlama düzeyleri ve bu kavramlar hakkında sahip oldukları kavram yanılgıları ortaya çıkarmak amacıyla gerçekleştirildiği için betimsel bir araştırmadır. 


\section{2. Çalışma Grubu}

Araştırmanın çalışma grubunu Eğitim Fakültesi, Fizik Eğitimi Anabilim Dalı'nın 1, 2, 3, 4 ve 5. sınıflarında öğrenim gören toplam 89 fizik öğretmen adayı oluşturmaktadır. Uygulamaya katılan grubun \%76,4'ü kız (68 kişi), \%23,6's1 erkek (21 kişi) öğrencilerden oluşmaktadır.

\subsection{Veri Toplama Aracı}

Fizik öğretmen adaylarının 1sı, sıcaklık ve iç enerji kavramları ile ilgili anlama düzeylerini ve kavram yanılgılarını ortaya çıkarmak için Gülbaş (2013) tarafından geliştirilmiş olan üçaşamalı "Isı, Sıcaklık ve İç Enerji Kavram Testi" (ISİEKT) kullanılmıştır. ISİEKT, ortaöğretim 11. Sınıf öğrencilerine yönelik geliştirilmiş üç-aşamalı bir testtir (Gülbaş 2013). Dolayısıyla bu çalışmada, fizik öğretmen adaylarının 1sı, sıcaklık ve iç enerji kavramları ile ilgili anlama düzeyleri ve kavram yanılgıları incelenmeden önce ISİEKT'nin geçerliği ve güvenilirliği tekrar test edilmiştir.

ISİEKT'de üç kavram yanılgısına odaklanılmıştır. ISİEKT ile ölçülen kavram yanılgıları şunlardır: 1. bir cismin 1SıS1 cismin büyüklüğüne bağlıdır, 2. bir cismin sıcaklı̆̆g cismin büyüklüğüne bağlıdır, 3. iç enerji cismin sahip olduğu 1sı miktarıdır. Literatürde, cisimlerin ısısının ve sıcaklığının o cismin büyüklügüne bağlı olduğuna ilişkin kavram yanılgılarının belirlenmesine yönelik çok sayıda çalışma vardır. Ancak, bu çalışmalarda genellikle 1sı ve sıcaklık konusu ile ilgili birçok kavram yanılgısı aynı anda incelenmektedir. Yapılan çalışmalarda kullanılan ölçme araçlarında her kavram yanılgısını ölçen eşit ve yeterli sayıda soru bulunmaması (Eryılmaz, 2010) nedeniyle tespit edilen kavram yanılgılarını detaylı olarak incelemek mümkün olmamaktadır. Ayrıca, çok sayıda kavram yanılgısına odaklanan etkili üçaşamalı teşhis testlerin bile geçerlik ve güvenirlik sorunlarının olduğu bilinmektedir (Eryılmaz, 2010). Bu nedenle, bu çalışmada öğretmen adaylarının kavram yanılgılarını daha detaylı incelemek, öğretmen adaylarının kavram yanılgılarına ilişkin geçerli ve güvenilir veriler toplamak amacıyla sadece üç kavram yanılgısına odaklanılmıştır ve bu amaca yönelik ISİEKT kullanılmıştır.

ISIEEKT, örnek birer durumu anlatan dört temel soru içermektedir. Temel soruların her birinde 1sı, sıcaklık ve iç enerji konusu ile ilgili üç adet alt soru bulunmaktadır. Temel sorularda verilen bilgilere göre üç-aşamalı alt sorular cevaplanmaktadır. Birinci aşama sorularında, örnek durumlarda ifade edilen cisimlerin 1s1, sıcaklık ve iç enerjilerinin karşılaştırılması istenmektedir. İkinci aşama sorularında, birinci aşama sorularına verilen cevabın nedeni sorulmaktadır. Üçüncü aşama sorularında ise öğretmen adaylarının, birinci ve ikinci aşamada verdikleri cevaptan emin olup olmadığı sorulmaktadır. Testte dört tane temel soru, on iki tane birinci aşama sorusu, on iki tane ikinci aşama sorusu ve on iki tane üçüncü aşama sorusu yer almaktadır. Üç-aşamalı testten alınabilecek puanlar 0 ile 12 arasındadır.

\subsection{Verilerin Analizi}

ISİEKT, fizik öğretmen adaylarına uygulandıktan sonra öğrenci cevapları Microsoft Excel Office programına işlenmiştir. Öğretmen adaylarının 1sı, sıcaklık ve iç enerji kavramı ile ilgili anlama düzeyleri doğru cevap anahtarına göre, kavram yanılgıları ise kavram yanılgısı cevap anahtarına göre puanlanmıştır. Doğru cevap anahtarı ve kavram yanılgısı cevap anahtarı kullanılarak toplam yedi puan türü elde edilmiştir. Bu puanlar; doğru cevap puanları-1, doğru cevap puanları-2, doğru cevap puanlar1-3, kavram yanılgıs1 puanlar1-1, kavram yanılgıs1 puanları-2, kavram yanılgısı puanlar1-3 ve güven seviyeleridir. Tablo 1'de bu puanların nasıl elde edildiği gösterilmiştir. 
Tablo 1: Doğru cevapların ve kavram yanılgısı cevaplarının puanlanması

\begin{tabular}{|c|c|}
\hline Puanlar & Açıklama \\
\hline Doğru cevap puanlar1-1: & $\begin{array}{l}\text { Sadece birinci aşama sorularından (bir-aşamalı sorular) } \\
\text { alınan puanların toplanması ile elde edilir. Birinci aşama } \\
\text { sorusuna verilen cevap doğru ise } 1 \text {, aksi durumda } 0 \text { puan } \\
\text { verilir. }\end{array}$ \\
\hline Doğru cevap puanları-2: & $\begin{array}{l}\text { Birinci aşama ve ikinci aşama sorularının tek bir soru olarak } \\
\text { kodlanıp (iki-aşamalı sorular), alınan puanların toplanması } \\
\text { ile elde edilir. Birinci aşama sorusuna verilen cevap doğru } \\
\text { ise } 1 \text {, aksi durumda } 0 \text { puan verilir. }\end{array}$ \\
\hline Doğru cevap puanlar1-3: & $\begin{array}{l}\text { Birinci aşama, ikinci aşama ve üçüncü aşama sorularının tek } \\
\text { bir soru olarak kodlanıp (üç-aşamalı sorular), alınan } \\
\text { puanların toplanması ile elde edilir. Birinci aşama ve ikinci } \\
\text { aşama sorularına birlikte verilen cevap doğru, üçüncü aşama } \\
\text { sorusuna verilen cevap "eminim" ise } 1 \text {; aksi durumda } 0 \\
\text { puan verilir. }\end{array}$ \\
\hline Kavram yanılg1s1 puanlar1-1: & $\begin{array}{l}\text { Sadece birinci aşama sorularından (bir-aşamalı sorular) } \\
\text { alınan puanların toplanması ile elde edilir. Birinci aşama } \\
\text { sorusuna verilen cevap kavram yanılgısı ise } 1 \text {, aksi durumda } \\
0 \text { puan verilir. }\end{array}$ \\
\hline Kavram yanılgısı puanları-2: & $\begin{array}{l}\text { Birinci aşama ve ikinci aşama sorularının tek bir soru olarak } \\
\text { kodlanıp (iki-aşamalı sorular), alınan puanların toplanması } \\
\text { ile elde edilir. Birinci aşama ve ikinci aşama sorusuna } \\
\text { birlikte verilen cevap kavram yanılgısı ise } 1 \text {, aksi durumda } 0 \\
\text { puan verilir. }\end{array}$ \\
\hline Kavram yanılgis1 puanlar1-3: & $\begin{array}{l}\text { Birinci aşama, ikinci aşama ve üçüncü aşama sorularının tek } \\
\text { bir soru olarak kodlanıp (üç-aşamalı sorular), alınan } \\
\text { puanların toplanması ile elde edilir. Birinci aşama ve ikinci } \\
\text { aşama sorusuna birlikte verilen cevap kavram yanılgısı, } \\
\text { üçüncü aşama sorusuna verilen cevap "eminim" ise 1; aksi } \\
\text { durumda } 0 \text { puan verilir. }\end{array}$ \\
\hline Güven seviyesi: & $\begin{array}{l}\text { Sadece üçüncü aşama sorularından alınan puanların } \\
\text { toplanması ile elde edilir. Üçüncü aşama sorusu "eminim" } \\
\text { olarak yanıtlanmışsa } 1 \text {, aksi durumda } 0 \text { puan verilir. }\end{array}$ \\
\hline
\end{tabular}

Öğretmen adaylarının anlama düzeyleri ve kavram yanılgıları hakkında daha detaylı bilgiler edinmek için ISİEKT'deki üç-aşamalı sorular farklı biçimlerde incelenmiştir. Üç-aşamalı soruların bir-aşamalı ve iki-aşamalı sorulara göre, kavram yanılgılarını ve anlama düzeylerini daha etkili şekilde tespit ettiği ve kavram yanılgılarını bilgi eksikliklerinden ayırt edebildiğ bilinmektedir (Eryılmaz ve Sürmeli, 2002; Eryılmaz, 2010). Bu nedenle, ISİEKT'deki her üçaşamalı sorudaki aşama soruları farklı şekillerde kodlanarak testin bu gücü ortaya çıkarılmaya çalışılmıştır. ISIEEKT, sadece birinci aşama soruları (bir-aşamalı sorular) kodlanarak bir-aşamalı test; birinci ve ikinci aşama soruları birlikte (iki-aşamalı sorular) kodlanarak iki-aşamalı test; birinci, ikinci ve üçüncü aşama soruları birlikte (üç-aşamalı sorular) kodlanarak üç-aşamalı test olarak ele alınmıştır. Bu puanlama yapılırken, ISİEKT'deki sorular bir-aşamalı, iki-aşamalı ve üç-aşamalı sorularmış gibi düşünülerek bütün soru tiplerine verilen doğru cevapların yüzdeleri ve kavram yanılgısı cevaplarının yüzdeleri Microsoft Excel Office programı kullanılarak hesaplanmıştır. Doğru cevapların ve kavram yanılgısı cevapları puanlanırken Tablo 1'de belirtilen kodlamalar kullanılmıştır.

ISİEKT, 11. Sınıf öğrencilerine yönelik geliştirilmiş, geçerliği ve güvenirliği belirlenmiş bir testtir. Bu nedenle, fizik öğretmen adaylarına uygulanan ISİEKT'nin geçerliği ve güvenirliği tekrar incelenmiştir. Testin yapı geçerliğine ilişkin kanıtlar toplamak için doğru cevap puanları-3 ve kavram yanılgısı puanları-3 açımlayıcı faktör analizi ile incelenmiştir. Ayrıca testin yapı geçerliğini incelemek için doğru cevap puanları-2 ile güven seviyeleri arasındaki Pearson momentler çarpımı korelasyon katsayısı da hesaplanmıştır. Bu analizler için SPSS 17.0 paket programı kullanılmıştır. ISİEKT'nin kapsam geçerliği için testteki yanlış sebepli doğruların 
yüzdeleri ve doğru sebepli yanlışların yüzdeleri hesaplanmıştır. ISİEKT'nin güvenirliğine ilişkin kanıtlar bulmak için Cronbach alfa güvenirlik katsayısı hesaplanmıştır.

Öncelikle, ISİEKT'nin yapı geçerliğine kanıtlar sağlamak amacıyla öğretmen adaylarının testteki üç-aşamalı sorulardan aldıkları doğru cevap puanları (doğru cevap puanları-3) ve kavram yanılgısı puanları (kavram yanılgısı puanları-3) için açımlayıcı faktör analizi ayrı yapılmıştır. Doğru cevap puanları-3 ve kavram yanılgıs1 puanlar1-3'ün nasıl elde edildiği Tablo 1'de gösterilmiştir. Doğru cevap puanlar1-3, testteki bütün üç-aşamalı sorulara verilen doğru cevapların puanlanması ile elde edilirken, kavram yanılgısı puanları-3 testteki bütün üç-aşamalı sorulara verilen kavram yanılgısı niteliğindeki cevapların puanlanması ile elde edilmektedir.

Doğru cevap puanları-3 ve kavram yanılgısı puanları-3 açımlayıcı faktör analizi ile incelenmeden önce, verilerin faktör analizine uygunluğu değerlendirilmiştir. Bu amaçla Barlett testi yapılmış ve Kaiser-Meyer-Olkin (KMO) değeri incelenmiştir. Doğru cevap puanları-3 için Barlett testi sonucunun $\left[x^{2}=787.251 ; \mathrm{p}<.05\right]$ istatistiksel olarak anlamlı olduğu ve KMO değerinin .771 olduğu tespit edilmiştir. Kavram yanılgısı puanları-3 için Barlett testi sonucunun $\left[x^{2}=533.673 ; \mathrm{p}<.05\right]$ istatistiksel olarak anlamlı olduğu ve KMO değerinin .725 olduğu belirlenmiştir. Veri seti üzerinde faktör analizi yapabilmek için KMO değerinin minimum .60 olması gerektiği ifade edilmektedir (Pullant, 2001). Analiz sonuçları, veri setine ait KMO değerlerinin önerilen KMO değerinden daha büyük olduğunu göstermiştir. Bu nedenle, veri setinin açımlayıcı faktör analizi yapmaya uygun olduğuna karar verilmiştir.

Doğru cevap puanları-3 için yapılan faktör analizi sonuçları, testi oluşturan faktörlerin toplam varyansın \%78'ini açıkladığını ve testin üç faktörden oluştuğunu göstermiştir. Bu faktörler altında toplanan üç-aşamalı sorular sırasıyla 1sı, sıcaklık ve iç enerji kavramı ile ilgili sorulardır. Testi oluşturan bu faktörlerin Cronbach alfa güvenirlik katsayısı sırasıyla .93, .90 ve .86 'dır. Kavram yanılgısı puanları-3 için yapılan faktör analizi incelemesinde, testi oluşturan bu faktörlerin toplam varyansın \%69'unu açıkladığı ve testin üç faktörden oluştuğu belirlenmiştir. Faktörler altında toplanan üç-aşamalı sorular sırasıyla 1s1, iç enerji ve sıcaklık kavramı ile ilgilidir. Faktörlerin Cronbach alfa güvenirlik katsayısı sırasıyla $.89, .77$ ve .84 'tür.

ISİEKT'nin yapı geçerliğine kanıtlar bulmak için Cataloglu (2002) tarafindan önerilen diğer bir yöntem kullanılmıştır. Cataloglu (2002) öğrencilerin testten aldıkları puanlar ile testte verdikleri cevaplardan emin olma düzeyleri arasında pozitif bir korelasyonun olmasını testin geçerliğinin bir kanıtı olarak görmektedir. Üç-aşamalı testlerin yap1 geçerliğini incelemek için çeşitli araştırmalarda da (Aydın, 2007; Kutluay, 2005; Peşman, 2005; Peşman ve Eryılmaz, 2010; Türker, 2005) kullanılan bu analiz ISİEKT için de kullanılmıştır. Bunun için ISIEEKT'nin iki-aşamalı sorularından elde edilen doğru cevap puanları (doğru cevap puanları-2) ile sadece üçüncü aşama sorusundan elde edilen ve güven seviyesini ifade eden puanlar arasındaki Pearson momentler çarpımı korelasyon katsayısı hesaplanmıştır. Doğru cevap puanları-2'nin nasıl elde edildiği Tablo 1'de gösterilmiştir. Korelasyon analizi sonuçları, doğru cevap puanları-2 ve güven seviyeleri arasında pozitif ve istatistiksel olarak anlamlı bir ilişkinin $(r=.23 ; p<.05)$ olduğunu göstermiş ve testin yapı geçerliğine ilişkin olumlu kanıtlar sunmuştur.

Hestenes ve Halloun'a (1995) göre bir testin kapsam geçerliği testteki yanlış sebepli doğruların ve doğru sebepli yanlışların oranı ile ilişkilidir. Testin kapsam geçerliği açısından, testteki yanlış sebepli doğruların oranı ve doğru sebepli yanlışların oranının \%10'dan daha az olması gerektiği vurgulanmaktadır (Hestenes ve Halloun, 1995). Bu nedenle, ISİEKT'deki doğru sebepli yanlışlar ve yanlış sebepli doğruların oranları hesaplanmıştır. Doğru sebepli yanlışların oranının hesaplanması sırasında üç-aşamalı her soru için kodlama yapılmış, birinci aşama sorusunu yanlış, ikinci aşama sorusunu doğru olarak cevaplamış ve üçüncü aşama sorusuna "eminim" cevabını vermiş öğrencilere 1, aksi durumda 0 puan verilmiştir (Eryılmaz, 2010). Yanlış sebepli doğruların oranı hesaplanırken, üç-aşamalı her soru için kodlama yapılmış, birinci aşama sorusunu doğru, ikinci aşama sorusunu yanlış olarak cevaplamış ve üçüncü aşama 
sorusuna "eminim" cevabını vermiş öğrencilere 1, aksi durumda 0 puan verilmiştir (Eryılmaz, 2010). Daha sonra elde edilen toplam puanlar, test sorularına verilen toplam cevap sayısına (Toplam cevap sayısı=Katılımcı sayısı*Soru sayısı) bölünerek doğru sebepli yanlışlar ve yanlış sebepli doğruların oranı elde edilmiştir (Aydın, 2007). Bu çalışmada, testteki doğru sebepli yanlışlar ve yanlış sebepli doğruların oranı sırasıyla $\% 3$ ve $\% 10$ olarak tespit edilmiştir. Bu sonuçlar, Hestenes ve Halloun'un (1995) belirtmiş olduğu kriterlerle tutarlı olup, testin kapsam geçerliğinin olduğunu göstermektedir. Ayrıca ISİEKT'nin güvenirliğini incelemek için testten elde edilen doğru cevap puanları-3 ve kavram yanılgısı puanları-3 için Cronbach Alfa güvenirlik katsayısı hesaplanmış, sırasıyla .78 ve .64 olarak belirlenmiştir. Analiz sonuçları, üç-aşamalı ISİEKT'nin yap1 geçerliği, kapsam geçerliği ve güvenirliğine ilişkin olumlu kanıtlar sunmuştur. Ayrıca bu sonuçlar, ortaöğretim 11. sınıf öğrencilerine yönelik geliştirilmiş olan ISİEKT'nin fizik öğretmen adaylarının 1sı, sıcaklık ve iç enerji kavramları ile ilgili anlama düzeylerini ve kavram yanılgılarını belirlemek için de geçerli ve güvenilir olarak kullanılabileceğini göstermiştir.

\section{BULGULAR}

Fizik öğretmen adaylarının 1sı, sıcaklık ve iç enerji kavramlarını anlama düzeylerini detaylı olarak incelemek için ISİEKT'deki aşamalı sorular farklı şekilde kodlanmış ve sorular bir-aşamalı (sadece birinci aşama), iki-aşamalı (birinci ve ikinci aşama) ve üç-aşamalı sorular (birinci, ikinci ve üçüncü aşama) (Bkz. Tablo 1) olarak ayrı ayrı değerlendirilmiştir. Soruların bir-aşamalı, iki-aşamalı ve üç-aşamalı olarak değerlendirilmesiyle hesaplanan doğru cevap yüzdeleri Şekil 1'de gösterilmiştir. Öğretmen adaylarının ortalama \%40'nın bir-aşamalı, ortalama \%26'sının iki-aşamalı, ortalama \%19'unun üç-aşamalı sorulara doğru cevaplar verdiği belirlenmiştir. Bir-aşamalı sorulardan üç-aşamalı sorulara doğru gidildikçe testteki soruların doğru cevaplanma oranları azalmıştır. Bu oranlar, bir-aşamalı, iki-aşamalı ve üç-aşamalı olarak incelenen sorulara verilen doğru cevapların oranlarının ortalamasıdır. Bu ortalamalar, testteki 1sı, sıcaklık ve iç enerji ile ilgili bütün sorulara verilen doğru cevapları kapsadığından, her üç kavramla ilgili anlama düzeyinin derecesini ifade eden genel bir göstergedir. Bir-aşamalı sorulardan üç-aşamalı sorulara doğru gidildikçe testteki soruların doğru cevaplanma oranları azalmıştır.

Şekil 1'de görüldüğü gibi, bir-aşamalı sorular ile iki-aşamalı soruların ortalama doğru cevaplanma yüzdeleri arasında yaklaşı \% $\% 14$ 'lük fark vardır. Bu oran birinci aşama sorularına doğru cevap veren öğretmen adaylarının \%14'ünün ikinci aşama sorularını doğru cevaplayamadıklarını ifade etmektedir. Bu farkın \%10'u yanlış sebepli doğruların oranından kaynaklanmaktadır. Yanlış sebepli doğruların oranı, birinci aşama sorusunu doğru cevapladığı halde önceki cevabının nedeninin sorulduğu ikinci aşama sorusunu doğru yanıtlayamayan ve üçüncü aşamada verdiği cevaplardan emin olduğunu belirten kişilerin oranını ifade etmektedir. Üç-aşamalı sorular ile iki-aşamalı soruların ortalama doğru cevaplanma yüzdeleri arasındaki fark ise yaklaşık \%7'dir. Yani bazı öğretmen adayları testteki iki-aşamalı sorulara doğru cevap verdikleri halde cevaplarından emin olmadıklarını söylemiştir. Bu durum, öğretmen adaylarının bilgi eksikliklerinin olduğunu göstermektedir. 


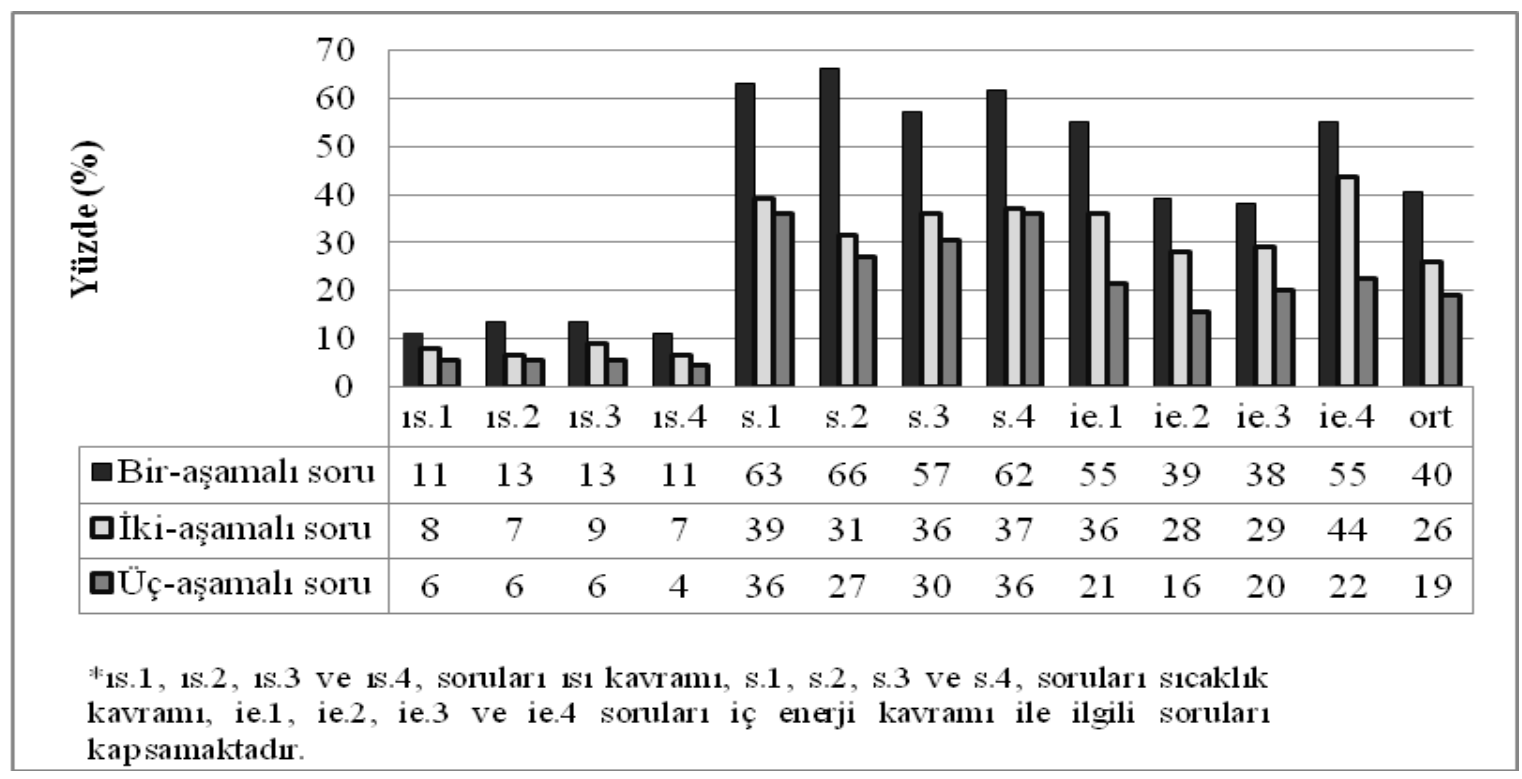

Şekil 1. Bir-aşamalı, iki-aşamalı ve üç-aşamalı olarak değerlendirilen ISİEKT sorularına verilen doğru cevapların yüzdeleri

Şekil 1'de, ISİEKT'deki 1s1, sıcaklık ve iç enerji kavramları ile ilgili soruları ve bu sorulara verilen doğru cevapların yüzdeleri görülmektedir. Öğretmen adaylarının 1s1, sıcaklık ve iç enerji kavramları ile ilgili anlama düzeyleri hakkında daha gerçekçi bilgiler edinmek amacıyla testteki sorular üç-aşamalı olarak değerlendirilmiştir. Buna göre, üç-aşamalı soruların doğru cevaplanma yüzdeleri 1sı ile ilgili sorular için \%4 ile \%6 arasında, sıcaklıkla ilgili sorular için \%27 ile \%36, iç enerji ile ilgili sorular için \%16 ile \%22 arasında değişmektedir. ISİEKT'deki 1sı ile ilgili dört üç-aşamalı soruda aynı ortamda yeterince uzun süre bekletilmiş olan aynı malzemeden yapılmış fakat büyüklükleri farklı iki cismin 1sısının karşılaştırılması istenmiştir. Bu dört soruya (1s.1, 1s.2, 1s.3 ve 1s.4) verilen doğru cevapların ortalamas1 \%5'tir. Buna göre, öğretmen adaylarının ortalama $\% 5$ 'i cisimlerin 1sısından bahsedilemeyeceği için cisimlerin 1sısının karşılaştırılamayacağını söylemiştir. ISİEKT'deki sıcaklık ile ilgili dört üç-aşamalı soruda aynı ortamda yeterince uzun süre bekletilmiş olan aynı malzemeden yapılmış fakat büyüklükleri farklı iki cismin sıcaklıklarının karşılaştırılması istenmiştir. Bu dört soruya (s.1, s.2, s.3 ve s.4) verilen doğru cevapların ortalamas $\% 32$ 'dir. Buna göre, öğretmen adaylarının ortalama \%32'si aynı ortamda yeterince uzun süre bekletilmiş olan aynı malzemeden yapılmış iki cismin sıcaklıklarının eşit olduğunu, çünkü bir cismin sıcaklığının o cismin büyüklüğüne bağlı olmadığını söylemiştir. ISİEKT'de yer alan iç enerji ile ilgili dört üç-aşamalı soruda ise aynı ortamda yeterince uzun süre bekletilmiş olan aynı malzemeden yapılmış fakat büyüklükleri farklı iki cismin iç enerjilerinin karşılaştırılması istenmiştir. Bu dört soruya (ie.1, ie.2, ie.3 ve ie.4) verilen doğru cevapların ortalaması \%20'dir. Buna göre, öğretmen adaylarının ortalama $\% 20$ 'si bir cismin iç enerjisinin cismin büyüklüğüne bağlı olduğunu ifade etmiştir.

Fizik öğretmen adaylarının 1sı, sıcaklık ve iç enerji kavramları ile ilgili kavram yanılgılarını detaylı olarak incelemek için testteki aşamalı sorular farklı şekilde kodlanmış ve sorular bir-aşamalı (sadece birinci aşama), iki-aşamalı (birinci ve ikinci aşama) ve üç-aşamalı (birinci, ikinci ve üçüncü aşama) sorular olarak ayrı ayrı değerlendirilmiştir (Bkz. Tablo 1). Soruların bir-aşamalı, iki-aşamalı ve üç-aşamalı olarak değerlendirilmesi sonucu hesaplanan kavram yanılgısı cevaplarının yüzdeleri Şekil 2'de gösterilmiştir. Öğretmen adaylarının ortalama $\% 47$ 'sinin bir-aşamalı, ortalama \%33'ünün iki-aşamalı, ortalama \%24'ünün üç-aşamalı sorulara kavram yanılgısı içeren cevaplar verdikleri belirlenmiştir. Bu oranlar, bir-aşamalı, iki-aşamalı ve 
üç-aşamalı olarak incelenen sorulara verilen kavram yanılgısı cevaplarına ait oranların ortalamasıdır. Bu ortalamalar, testteki 1sı, sıcaklık ve iç enerji ile ilgili bütün sorulara verilen kavram yanılgısı cevaplarını kapsadığından, her üç kavramla ilgili kavram yanılgısı düzeyini ifade eden genel bir göstergedir. Bir-aşamalı sorulardan üç-aşamalı sorulara doğru gidildikçe sorulara verilen kavram yanılgısı cevapların oranında azalma meydana gelmiştir.

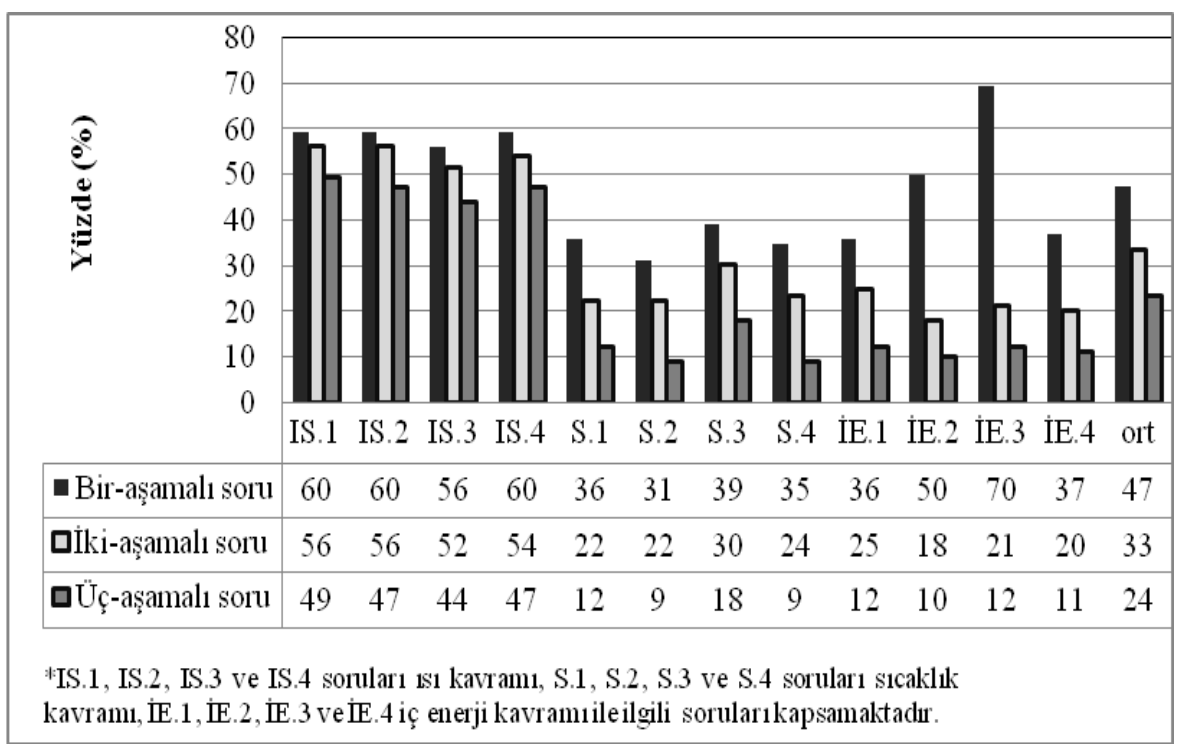

\section{Şekil 2. Bir-aşamalı, iki-aşamalı ve üç-aşamalı olarak değerlendirilen ISİEKT sorularına verilen kavram yanılgısı cevaplarının yüzdeleri}

Şekil 2'de görüldüğü gibi, bir-aşamalı sorular ile iki-aşamalı sorulara verilen kavram yanılgısı cevaplarının ortalama yüzdeleri arasında yaklaşık \%14'lük fark vardır. Bu oran birinci aşama sorularına kavram yanılgısı cevabı veren öğretmen adaylarının \%14'ünün ikinci aşama sorularına kavram yanılgısı cevabı dışında bir cevap verdiklerini ifade etmektedir. Bu farkın \%3'ü doğru sebepli yanlışların oranından kaynaklanmaktadır. Doğru sebepli yanlışların oranı, birinci aşama sorusunu yanlış cevapladığı halde önceki cevabının nedeninin sorulduğu ikinci aşama sorusuna doğru yanıt veren ve üçüncü aşamada verdiği cevaplardan emin olduğunu belirten kişilerin oranını ifade etmektedir. Üç-aşamalı sorular ile iki-aşamalı sorulara verilen kavram yanılgısı cevaplarının ortalama yüzdeleri arasındaki fark ise yaklaşık \%9'dur. Bir başka deyişle, bazı öğretmen adayları testteki iki-aşamalı sorulara kavram yanılgısı içeren cevaplar vermelerine rağmen üçüncü aşama sorularında cevaplarından emin olmadıklarını belirtmiştir. $\mathrm{Bu}$ durum öğretmen adaylarının bilgi eksikliklerinin olduğunu ifade etmektedir.

Şekil 2'de, ISİEKT'deki 1sı, sıcaklık ve iç enerji kavramları ile ilgili soruları ve bu sorulara verilen kavram yanılgısı cevaplarının yüzdeleri görülmektedir. Öğretmen adaylarının 1sı, sıcaklık ve iç enerji kavramları ile ilgili kavram yanılgıları hakkında daha gerçekçi bilgiler edinmek amacıyla testteki sorular üç-aşamalı olarak değerlendirilmiştir. Buna göre, üç-aşamalı sorulara verilen kavram yanılgısı cevaplarının yüzdeleri 1sı ile ilgili sorular için \%44 ile \%49 arasında, sıcaklıkla ilgili sorular için \%9 ile \%18 arasında, iç enerji ile ilgili sorular için \%10 ile \%12 arasında değişmektedir. Testin ısı ile ilgili dört üç-aşamalı sorusu (IS.1, IS.2, IS.3 ve IS.4) ile "bir cismin 1sıs1 cismin büyüklüğüne bağlıdır" kavram yanılgısı ölçülmektedir. Bu dört soruya verilen kavram yanılgısı cevaplarının ortalaması \%47'dir. Yani öğretmen adaylarının ortalama $\% 47$ 'si aynı ortamda yeterince uzun süre bekletilmiş olan aynı malzemeden yapılmış iki cismin 1sısının cisimlerin büyüklüğüne bağlı olduğunu düşünmektedir. Testin sıcaklık ile ilgili dört üç- 
aşamalı sorusu (S.1, S.2, S.3 ve S.4) ile "bir cismin sıcaklığı cismin büyüklüğüne bağlıdır" kavram yanılgısı ölçülmektedir. Bu dört soruya verilen kavram yanılgısı cevaplarının ortalaması $\% 12$ 'dir. Yani öğretmen adaylarının ortalama \%12'si aynı ortamda yeterince uzun süre bekletilmiş olan aynı malzemeden yapılmış iki cismin sıcaklıklarının cisimlerin büyüklüğüne bağl1 olduğunu düşünmektedir. Testin iç enerji ile ilgili dört üç-aşamalı sorusu (İE.1, İE.2, İE.3 ve İE.4) ile "iç enerji cismin sahip olduğu 1sı miktarıdır" kavram yanılgısı ölçülmektedir. Bu dört soruya verilen kavram yanılgısı cevaplarının ortalamas1 \%12'dir. Yani öğretmen adaylarının ortalama \%12'si iç enerjinin cismin sahip olduğu 1sı miktarı ile ilişkili olduğunu düşünmektedir. Başka bir deyişle, bazı öğretmen adayları aynı ortamda yeterince uzun süre bekletilmiş olan aynı malzemeden yapılmış iki cisimden, 1sısı daha fazla olan cismin iç enerjisinin de daha fazla olacağını veya 1sısı eşit olan cisimlerin iç enerjilerinin de eşit olacağını düşünmektedir.

\section{TARTIŞMA ve SONUÇ}

$\mathrm{Bu}$ çalışmada fizik öğretmen adaylarının 1sı, sıcaklık ve iç enerji kavramları ile ilgili anlama düzeyleri ve kavram yanılgıları incelenmiştir. Ancak, öncelikle bu amaç için kullanılan ISİEKT'nin geçerliği ve güvenirliği tekrar incelenmiştir. ISİEKT'nin fizik öğretmen adaylarının 1S1, sıcaklık ve iç enerji kavramları ile ilgili anlama düzeylerinin ve kavram yanılgılarının belirlenmesinde kullanılabilecek geçerli ve güvenilir bir test olduğu saptanmıştır.

Araştırmada, öğretmen adaylarının \%32'sinin "bir cismin sıcaklığının onun büyüklüğü ile ilişkili olmadığını" düşündüğünü belirlenmiştir. "Isının sıcaklık farkı nedeniyle transfer edilen enerji olduğu" ve "bu nedenle bir cismin 1sıya sahip olamayacağı" bilgisine sahip öğretmen adaylarının oranı $\% 5$ olarak belirlenmiştir. Araştırma sonuçları, öğretmen adaylarının sıcaklık kavramı ile ilgili üç-aşamalı sorulara, 1Sı ve iç enerji kavramı ile ilgili sorulara göre daha fazla doğru cevaplar verdiklerini göstermiştir. Buna karşın, öğretmen adaylarının doğru cevaplamada en çok zorlandıkları soruların 1sı kavramı ile ilgili olduğu görülmüştür. Bu durum, öğretmen adaylarının 1sı kavramını anlama düzeylerinin düşük olduğunu göstermektedir.

Araştırmada, öğretmen adaylarının \%47'sinin "bir cismin 1sısının onun büyüklüğüne bağlı olduğuna" ilişkin kavram yanılgısına sahip oldukları görülmüştür. Bununla birlikte, "bir cismin sıcaklığının onun büyüklüğ̈̈ne bağlı olduğu" kavram yanılgısına sahip öğretmen adayları \%12 olarak belirlenmiştir. Öğretmen adaylarının 1sı kavramı ile ilgili üç-aşamalı sorulara, sıcaklık ve iç enerji kavramı ile ilgili sorulara kıyasla daha fazla kavram yanılgısı cevabı verdiklerini görülmüştür. ISİEKT'deki sorulara verilen kavram yanılgısı cevaplarının oranlarının yüksek olması, fizik öğretmen adaylarının 1sı kavramı ile ilgili anlama düzeylerinin yeterli olmadığı sonucunu desteklemektedir. Fizik öğretmen adaylarının bir nesnenin 1sısını ve sıcaklığını nesnelerin maddesel özellikleri yani nesnelerin büyüklükleri ile ilişkilendirerek açıkladıkları belirlenmiştir. Isı ve sıcaklık ile ilgili bu kavram yanılgıları nesne-tabanlı kavram yanılgıları olarak adlandırılmaktadır (Reiner et al. 2000). Literatürde farklı çalışma gruplarıyla gerçekleştirilen diğer çalışmalarda da benzer sonuçların elde edildiği görülmektedir. Örneğin, Gönen ve Akgün (2005) ve Kartal et al. (2011) fen bilgisi öğretmen adaylarının 1S1 ve sicaklık kavramlarını nesnelerin büyüklükleri ile ilişkilendirerek açıkladıklarını belirlemiştir. Benzer şekilde Alwan (2011), Libya'da gerçekleştirdiği çalışmada Eğitim Fakültesinin fizik, kimya, biyoloji ve matematik bölümlerinde okuyan öğrencilerin, bir cismin sicaklığını o cismin yapıldığı malzemeye ve cismin büyüklüğüne bağlı olarak açıkladıklarını tespit etmiştir.

Ayrıca çalışma kapsamında, öğretmen adaylarının \%20'sinin "bir cismin iç enerjisinin onun büyüklüğü ile doğru orantılı olduğunu" düşündüğü tespit edilmiştir. Buna karşın, öğretmen adaylarının \%12'sinin "iç enerjinin cismin sahip olduğu 1sı miktarı" olduğuna ilişkin kavram yanılgısının olduğu tespit edilmiştir. Bu kavram yanılgısına ilişkin Warren (1972) tarafından farklı bir çalışma grubunda gerçekleştirilmiş araştırmada, üniversitede fen ve mühendislik 
alanında öğrenim gören öğrencilerden 1Sı ve iç enerji kavramlarını tanımlamaları ve bu kavramlar arasındaki ilişkiyi açıklamaları istenmiş ve öğrencilerin "iç enerjinin bir cismin sahip olduğu 1sı miktarı" olduğunu düşündükleri tespit edilmiştir. Ancak bu düşüncenin bir kavram yanılgısı olduğu net olarak vurgulanmamıştır. ISİEKT'deki üç-aşamalı sorular ile öğretmen adaylarının verdikleri kavram yanılgısı cevaplarından emin oldukları belirlenebilmektedir. $\mathrm{Bu}$ nedenle bu çalışmadan elde edilen sonuçlar, "iç enerji cismin sahip olduğu 1s1 miktarıdır" düşüncesinin bir kavram yanılgısı olduğunu daha da netleştirmektedir.

Fizik öğretmen adaylarının nitelikli öğretmen olabilmeleri onların pedagojik formasyon bilgileri ve bazı duyuşsal özelliklerine bağlı olduğu kadar onların yeterli alan bilgisine sahip olmalarına, bir başka deyişle fiziği doğru kavramalarına da bağlıdır. Isı, sıcaklık ve iç enerji konusunun incelendiği bu çalışmadan elde edilen sonuçlar, fizik öğretmen adaylarının özellikle 1S1 kavramını anlama düzeylerinin yetersiz olduğunu ve 1S1 kavramı ile ilgili kavram yanılgılarının oranın oldukça yüksek olduğunu göstermiştir. $\mathrm{Bu}$ durum, fizik öğretmen adaylarının kendi kavram yanılgıları nedeniyle öğrencilerinin de kavram yanılgılarının oluşmasına sebep olabileceklerini düşündürmektedir. Gerek fizik öğretmen adaylarının 1sı, sıcaklık ve iç enerji konusu ile ilgili sahip oldukları kavram yanılgılarının giderilmesi gerekse kavram yanılgılarıyla ilgili farkındalıklarının artırılması açısından termodinamik dersi ve pedagojik formasyon dersleri oldukça önemlidir. Bu dersler kapsamında 1s1, sıcaklık ve iç enerji konusu ile ilgili kavram yanılgılarına dikkat çekilebilir ve bu kavram yanılgılarının giderilmesine ilişkin çeşitli çalışmalar yapılabilir.

Bu çalışma kapsamında kullanılan ISİEKT, 1sı, sıcaklık ve iç enerji ile ilgili sadece üç kavram yanılgısını teşhis etmeye odaklanmış üç-aşamalı testtir. Kavram yanılgılarının tespit edilmesinde oldukça etkili ölçme araçları olduğu belirtilen üç-aşamalı testler kullanılarak (Arslan et al. 2012; Eryılmaz, 2010; Ery1lmaz ve Sürmeli, 2002; Peşman ve Eryılmaz, 2010) termodinamik ile ilgili başka kavram yanılgılarının belirlenmesi önerilmektedir.

\section{KAYNAKLAR}

Alwan, A. A. (2011). Misconception of heat and temperature among physics students. Procedia Social and Behavioral Sciences, 12, 600-614.

Appleton, K. (1984). Children's ideas about hot and cold. Learning in science project (primary) (Working paper no. 127). Hamilton, New Zealand. Science Education Research Unit. (ERIC Document Reproduction Service No. ED 252 407)

Arslan, H. O., Cigdemoglu, C., \& Moseley C. (2012). A three-tier diagnostic test to assess pre-service teachers' misconceptions about global warming, greenhouse effect, ozone layer depletion, and acid rain. International Journal of Science Education, 34 (11), 1667-1686.

Aydın, Ö. (2007). Assessing tenth grade students' difficulties about kinematics graphs by a three-tier test. Published master thesis, Middle Technical University, Ankara.

Aydoğan, S., Güneş, B., ve Gülçiçek, Ç. (2003). Isı ve sıcaklık konusunda kavram yanılgıları [The misconceptions about heat and temperature]. Gazi Üniversitesi Ĕ̆itim Fakültesi Dergisi, 23 (2), 111-124.

Başer, M. (1996). Effect of conceptual instruction on understanding of heat and temperature concepts and science attitude. Unpublished master's thesis, Middle East Technical University, Ankara.

Beichner, R. J. (1994). Testing student interpretation of kinematics graphs. American Journal of Physics, 62 (8), 750 762.

Cataloglu, E. (2002). Development and validation of an achievement test in introductory quantum mechanics: The quantum mechanics visualization instrument. [Available online at: https://etda.libraries.psu.edu/paper/5937/1204$A B D$ ], Retrieved on August 8, 2012.

Clough, E. E., \& Driver, R. (1985) Secondary students' conceptions of the conduction of heat: Bringing together scientific and personal views. Physics Education, 20 (4), 176-182.

Erickson, G. L. (1980). Children view points of heat: A second look. Science Education, 64 (3), 323-336.

Erickson, G. L. (1979). Children's conceptions of heat and temperature. Science Education, 63 (2), 221-230. 
Eryılmaz, A. (2010). Development and application of three-tier heat and temperature test: Sample of bachelor and graduate student. Eurasian Journal of Educational Research, 40, 53-76.

Eryılmaz, A. ve Sürmeli E. (2002). Üç-aşamalı sorularla öğrencilerin 1sı ve sıcaklık konularındaki kavram yanılgılarının ölçülmesi.[Çevrim-içi:http://www.fedu.metu.edu.tr/ufbmek-5/bkitabi/PDF/Fizik/Bildiri/t110d.pdf], Erişim tarihi: 07 Şubat 2011.

Gönen, S. ve Akgün, A. (2005). Isı ve sıcaklık kavramları arasındaki ilişki ile ilgili olarak geliştirilen çalışma yaprağının uygulanabilirliğinin incelenmesi [The investigation of applicability of worksheet was developed about relationship between heat and temperature concepts]. Elektronik Sosyal Bilimler Dergisi, 3 (11), 92-106.

Gülbaş, E. (2013). Öğrencilerin ısı, sıcaklık ve iç enerji kavramlarını anlama düzeyleri ile öğrenme yönelimleri ve bazı duyuşsal karakteristikleri arasındaki ilişkinin incelenmesi. Yayınlanmış yüksek lisans tezi, Hacettepe Üniversitesi, Ankara.

Gürses, A., Doğar, Ç. ve Yalçın, M. (2002). Isı ve sıcaklık konusunun öğretiminde sürekli değerlendirmeye dayalı öğretimin etkinliğinin incelenmesi. [Çevrim-içi:http://www.fedu.metu.edu.tr/ufbmek5/bkitabi/PDF/Fizik/Bildiri/t110d.pdf], Erişim tarihi: 01 Mart 2012.

Harrison, A. G., Grayson, D. J., \& Treagust, D. F. (1999). Investigating a grade 11 student's evolving conceptions of heat and temperature. Journal of Research in Science Teaching, 36 (1), 55-87.

Hasan, S., Bagayoko, D., \& Kelley, E. L. (1999). Misconceptions and the certainty of response index (CRI). Physics Education, 34 (5), 294-299.

Hestenes, D., \& Halloun, I. (1995). Interpreting the force concept inventory. Physics Teacher, 33, 502-506.

Hollon, R. E., \& Anderson, C. W. (1986). Heat and temperature: A teaching module (Occasional Paper No 93). East Lansing. Inst. for Research on Teaching. (ERIC Document Reproduction Service No. ED 273 453)

Kaptan, F. ve Korkmaz, H. (2001). Hizmet öncesi sınıf öğretmenlerinin fen eğitiminde 1sı ve sıcaklıkla ilgili kavram yanılgıları [Primary school preservice teachers' misconceptions about heat and temperature in science teaching]. Hacettepe Üniversitesi Ĕ̈itim Fakültesi Dergisi, 21, 59-65.

Kartal, T., Öztürk, N., \& Yalvaç, H. G. (2011). Misconceptions of science teacher candidates about heat and temperature. Procedia Social and Behavioral Sciences, 15, 2758-2763.

Keleş, Ö., Ertaş, H., Uzun, N., \& Cansız, M. (2010). The understanding levels of preservice teachers of basic science concepts' measurement units and devices, their misconceptions and its causes. Procedia Social and Behavioral Sciences, 9, 390-394.

Kırıkkaya, E. B. ve Güllü D. (2008). İlköğretim beşinci sınıf öğrencilerinin 1s1-sıcaklık ve buharlaşma-kaynama konularındaki kavram yanılgıları [Fifth grade students' misconceptions about heat-temperature and evaporationboiling]. Elementary Education Online, 7 (1), 15-27.

Kutluay, Y. (2005). Diagnosis of eleventh grade students' misconceptions about geometric optic by a three-tier test. Published master thesis, Middle Technical University, Ankara.

Libarkin J. C., \& Kurdziel J. P. (2001). Research methodologies in science education assessing students' alternative conceptions. Journal of Geoscience Education, 49 (4), 378-383.

Osborne, R. J., \& Gilbert, J. K. (1980). A technique for exploring students' views of the world. Physics Education, 15, 376-379.

Peşman, H. (2005). Development of a three-tier test to assess ninth grade students' misconceptions about simple electric circuits. Published master thesis, Middle Technical University, Ankara.

Peşman, H., \& Eryılmaz, A. (2010). Development of a three-tier test to assess misconceptions about simple electric circuits. The Journal of Educational Research, 103, 208-222.

Pullant, J. (2001). SPSS survival manual. A step-by-step guide to data analyses using spss for Windows. Philadelphia, PA: Open University Press.

Reiner, M., Slotta, J. D., Chi, M. T. H., \& Resnick, L. B. (2000). Naive Physics Reasoning: A commitment to substance-based conceptions. Cognition and Instruction, 18 (1), 1-34.

Tan, K. C. D., Goh, N. K., Chia, L. S., \& Treagust, D. F. (2002). Development and application of a two-tier multiple choice diagnostic instrument to assess high school students' understanding of inorganic chemistry qualitative analysis. Journal of Research in Science Teaching, 39 (4), 283-301.

Tan, K. C. D., Taber, K. S., Goh, N. K., \& Chia, L. S. (2005). The ionisation energy diagnostic instrument: A two-tier multiple-choice instrument to determine high school students' understanding of ionisation energy. Chemistry Education Research and Practice, 6 (4), 180-197.

Thomaz, M. F., Malaquias I. M., Valente M. C., \& Antunes M. J. (1995). An attempt to overcome alternative conceptions related to heat and temperature. Physics Education, 30, 19-26. 
Turgut, Ü. ve Gürbüz, F. (2011). Isı ve sıcaklık konusunda 5e modeliyle öğretimin öğrencilerdeki kavramsal değişime ve onların tutumlarına etkisi. International Online Journal of Educational Sciences, 3 (2), 679-706.

Türker, F. (2005). Developing a three-tier test to assess high school students' misconceptions concerning force and motion. Published master thesis, Middle Technical University, Ankara.

Warren, J. W. (1972). The teaching of the concept of heat, Physics Education, 7, 41-44.

Wiser, M. (1986). The Differentiation of Heat and Temperature: An evaluation of the effect of microcomputer teaching on students' misconceptions (Technical Report 87-5). Educational Technology Center, Cambridge. (ERIC Document Reproduction Service No. ED 291 596)

Yağbasan, R. ve Gülçiçek Ç., 2003, Fen öğretiminde kavram yanılgılarının karakteristiklerinin tanımlanması. Pamukkale Üniversitesi Ĕgitim Fakültesi Dergisi, 1 (13), 102-120.

Yeşilyurt, M. (2006). Lise öğrencilerinin 1sı ve sıcaklık kavramları ile ilgili düşünceleri [High school students' views about heat and temperature concepts]. International Journal of Environmental and Science Education, 1 (1), 1-24.

\section{Extended Abstract}

As was emphasized in the constructivist approach, it is known that newly learned knowledge is structured on conceptual structures that already exist in the learner's mind. However, during this process of structuring, deficient or erroneous learning may take place as well as correct learning and even misconceptions, which are quite hard to remove, may also occur (Yağbasan ve Gülçiçek 2003). Various studies emphasize that teachers, who are known to have a significant influence on students' learning processes, should take into consideration these misconceptions (Libarkin and Kurdziel 2001). Therefore, it is important that before they begin their career, preservice physics teachers have information about students' misconceptions and know how these misconceptions can be eliminated. However, studies have found that not only students but also preservice teachers have some misconceptions (Alwan 2011; Gönen and Akgün 2005; Kaptan and Korkmaz 2001; Kartal, Öztürk, and Yalvaç 2011; Keleş, Ertaş, Uzun, and Cansız 2010). It is impossible for preservice physics teachers who have inadequate or incorrect knowledge or some misconceptions about concepts of physics to teach their students correct scientific knowledge about concepts of physics (Kaptan and Korkmaz 2001). Therefore, it is necessary to investigate the misconceptions of preservice physics teachers.

Concepts of heat and temperature are among the misconceptions that are frequently used in daily life and most commonly encountered in physics (Turgut and Gürbüz 2011; Yeşilyurt 2006). Although there are studies in the relevant literature about heat and temperature, there are not enough studies aimed at determining misconceptions about the topic of internal energy. In this study, the purpose was to determine preservice physics teachers' understandings and misconceptions about heat, temperature and internal energy, which are fundamental concepts of thermodynamics. The study group consisted of 89 preservice physics teachers who were first, second, third, fourth and fifth year students at Physics Education program. $76.4 \%$ of the participants were female (68 students) and $23.6 \%$ were male (21 students). The three-tier "Heat, Temperature and Internal Energy Concept Test" (HTIECT) which was developed by Gülbaş (2013), was used to determine preservice physics teachers' understandings and misconceptions about the concepts of heat, temperature and internal energy. Since HTIECT is a three-tier test developed for students in the eleventh grade in secondary education, the validity and reliability of HTIECT were tested before investigating the preservice physics teachers' understandings and misconceptions about heat, temperature and internal energy. The results of the analysis indicated that HTIECT, which was intended for students in the eleventh grade in secondary education, could also be used validly and reliably to determine preservice physics teachers' understandings and misconceptions about heat, temperature and internal energy.

In order to investigate preservice physics teachers' understandings and misconceptions about heat, temperature and internal energy in detail, the percentages of the correct answers they gave to the three-tier questions were calculated. In the study, the average percentage of the answers given to the three-tier questions in HTIECT was 32\% for temperature questions, $20 \%$ for internal energy questions and $5 \%$ for heat questions. According to these results, the average percentage of the correct answers given to the three-tier questions about temperature by preservice physics teachers is higher than the three-tier questions about heat and internal energy. In order to investigate preservice teachers' misconceptions about heat, temperature and internal energy, the percentages of the misconception answers given to the three-tier 
questions were calculated. The average percentage of the misconception answers given to the three-tier questions in HTIECT was found to be $12 \%$ for temperature questions, $12 \%$ for internal energy questions and $47 \%$ for heat questions. These findings indicated that the average percentage of misconception answers given to three-tier questions about heat were much higher than questions about temperature and internal energy.

The results of the study indicate that preservice physics teachers' understandings about heat were very low. According to this, the number of preservice teachers who have the knowledge that "heat is energy that is transferred due to differences in temperature" and that "therefore, an object cannot have heat" is quite low. Moreover, the fact that the rate of preservice physics teachers $(47 \%)$ who have the misconception that "the heat of an object depends on its size" is high supports this finding. However, the rate of preservice teachers who have the misconception that "the temperature of an object depends on its size" is $12 \%$. These misconceptions about heat and temperature are substance-based misconceptions (Reiner, Slotta, Chi, \& Resnick 2000). The results of the study showed that preservice physics teachers explained the concepts of heat and temperature on the basis of the material properties of objects, in other words their size. Studies by Gönen and Akgün (2005), Kartal et. al. (2011) and Alwan (2011) also obtained similar results. Gönen and Akgün (2005) and Kartal et. al. (2011) found that preservice science teachers explained the concepts of heat and temperature by linking them to the size of objects. Alwan (2011), on the other hand, found that physics, chemistry, biology and mathematics students at Faculty of Education, explained the temperature of an object on the basis of the material of which that object is made and the size of the object. Therefore, the findings obtained from this study are in conformity with the findings of the previous studies.

In this study, it was found that preservice physics teachers thought "internal energy is the amount of heat that an object has". A similar result was reached in a study conducted by Warren (1972). Warren (1972) asked students attending science and engineering departments at a university to define the concepts of heat and internal energy and explain the relationship between these concepts and found that students thought "internal energy is the amount of heat that an object has". However, since the use of three-tier questions in this study enabled us to determine definitively whether the students were sure of their misconception answers, the results of this study indicated that this idea of preservice physics teachers about the concept of internal energy was indeed a misconception.

\section{Kaynakça Bilgisi}

Gürçay, D., \& Gülbaş, E. (2016). Fizik öğretmen adaylarının 1sı, sıcaklık ve iç enerji ile ilgili kavram yanılgıları. Hacettepe Üniversitesi Eğitim Fakültesi Dergisi [Hacettepe University Journal of Education], 31(3), 461-474.

\section{Citation Information}

Gürçay, D., \& Gülbaş, E. (2016). Preservice physics teachers' misconceptions about heat, temperature and internal energy [in Turkish]. Hacettepe University Journal of Education [Hacettepe Üniversitesi Eğitim Fakültesi Dergisi], 31(3), 461-474. 